\title{
Akt/mTOR Role in Human Foetoplacental Vascular Insulin Resistance in Diseases of Pregnancy
}

\author{
Roberto Villalobos-Labra, ${ }^{1}$ Luis Silva, ${ }^{1,2}$ Mario Subiabre, ${ }^{1}$ Joaquín Araos, ${ }^{1}$ Rocío Salsoso, ${ }^{1,3}$ \\ Bárbara Fuenzalida, ${ }^{1}$ Tamara Sáez, ${ }^{1,2}$ Fernando Toledo, ${ }^{1,4}$ Marcelo González, ${ }^{5}$ \\ Claudia Quezada, ${ }^{6}$ Fabián Pardo, ${ }^{1,7}$ Delia I. Chiarello, ${ }^{1}$ Andrea Leiva, ${ }^{1}$ and Luis Sobrevia ${ }^{1,3,8}$ \\ ${ }^{1}$ Cellular and Molecular Physiology Laboratory (CMPL), Division of Obstetrics and Gynaecology, School of Medicine, Faculty of \\ Medicine, Pontificia Universidad Católica de Chile, 8330024 Santiago, Chile \\ ${ }^{2}$ Immunoendocrinology, Division of Medical Biology, Department of Pathology and Medical Biology, University of Groningen, \\ University Medical Center Groningen (UMCG), 9700 RB Groningen, Netherlands \\ ${ }^{3}$ Department of Physiology, Faculty of Pharmacy, Universidad de Sevilla, 41012 Seville, Spain \\ ${ }^{4}$ Department of Basic Sciences, Faculty of Sciences, Universidad del Bío-Bío, 3780000 Chillán, Chile \\ ${ }^{5}$ Vascular Physiology Laboratory, Department of Physiology, Faculty of Biological Sciences, Universidad de Concepción, 4070386 \\ Concepción, Chile \\ ${ }^{6}$ Institute of Biochemistry and Microbiology, Science Faculty, Universidad Austral de Chile, 5110566 Valdivia, Chile \\ ${ }^{7}$ Metabolic Diseases Research Laboratory, Center of Research, Development and Innovation in Health-Aconcagua Valley, School of \\ Medicine, Faculty of Medicine, Universidad de Valparaíso, San Felipe Campus, 2172972 San Felipe, Chile \\ ${ }^{8}$ University of Queensland Centre for Clinical Research (UQCCR), Faculty of Medicine and Biomedical Sciences, University of \\ Queensland, Herston, Brisbane, QLD 4029, Australia
}

Correspondence should be addressed to Luis Sobrevia; sobrevia@me.com

Received 1 June 2017; Accepted 15 August 2017; Published 14 September 2017

Academic Editor: Christian Wadsack

Copyright (c) 2017 Roberto Villalobos-Labra et al. This is an open access article distributed under the Creative Commons Attribution License, which permits unrestricted use, distribution, and reproduction in any medium, provided the original work is properly cited.

\begin{abstract}
Insulin resistance is characteristic of pregnancies where the mother shows metabolic alterations, such as preeclampsia (PE) and gestational diabetes mellitus (GDM), or abnormal maternal conditions such as pregestational maternal obesity (PGMO). Insulin signalling includes activation of insulin receptor substrates 1 and 2 (IRS1/2) as well as Src homology 2 domain-containing transforming protein 1 , leading to activation of 44 and $42 \mathrm{kDa}$ mitogen-activated protein kinases and protein kinase $\mathrm{B} / \mathrm{Akt}$ (Akt) signalling cascades in the human foetoplacental vasculature. PE, GDM, and PGMO are abnormal conditions coursing with reduced insulin signalling, but the possibility of the involvement of similar cell signalling mechanisms is not addressed. This review aimed to determine whether reduced insulin signalling in PE, GDM, and PGMO shares a common mechanism in the human foetoplacental vasculature. Insulin resistance in these pathological conditions results from reduced Akt activation mainly due to inhibition of IRS1/2, likely due to the increased activity of the mammalian target of rapamycin (mTOR) resulting from lower activity of adenosine monophosphate kinase. Thus, a defective signalling via Akt/mTOR in response to insulin is a central and common mechanism of insulin resistance in these diseases of pregnancy. In this review, we summarise the cell signalling mechanisms behind the insulin resistance state in PE, GDM, and PGMO focused in the Akt/mTOR signalling pathway in the human foetoplacental endothelium.
\end{abstract}

\section{Introduction}

Insulin modulates D-glucose homeostasis, and a reduced response or a lack of response to this hormone (hereafter referred as "insulin resistance") is characteristic in several pathologies, including diabetes mellitus and obesity $[1,2]$. Insulin resistance tightly relates with abnormal responses of the vascular endothelium, that is, endothelial dysfunction, 


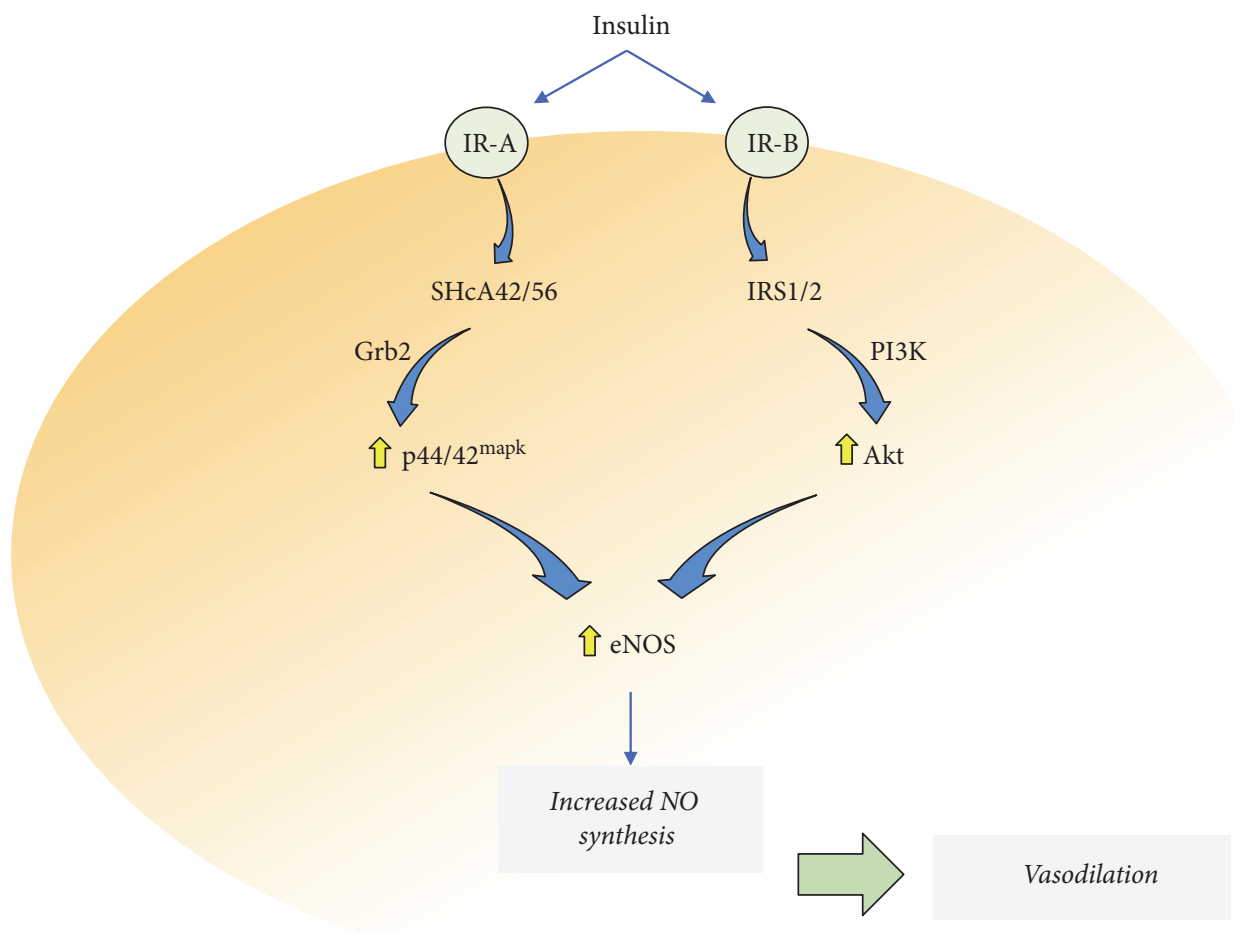

FIGURE 1: Insulin signalling in the human feotoplacental vasculature. Insulin activates insulin receptors A (IR-A) and B (IR-B) leading to recruitment and activation of insulin receptor substrates 1 and 2 (IRS1/2) and Src homology 2 domain-containing transforming protein 1 type A of 42 and $56 \mathrm{kDa}$ (SHcA42/56). IR-A activation causes preferential activation of SHcA42/56, which triggers signalling through the growth factor receptor-bound protein 2 (Grb2) cascade ending in higher (i) activity of the 44 and $42 \mathrm{kDa}$ mitogen-protein kinases $\left(\mathrm{p} 44 / 42^{\mathrm{mapk}}\right)$. IR-B activation causes preferential activation of IRS1/2, which triggers signalling through the phosphatidylinositol 3 kinase (PI3K) cascade ending in higher protein kinase B/Akt (Akt) activity. IR-A signalling and IR-B signalling increase the endothelial nitric oxide (NO) synthase (eNOS) activity to generate nitric oxide (NO). An increase in the NO synthesis results in relaxation of the foetoplacental vascular beds (vasodilation).

to vasoactive molecules including insulin and the endogenous nucleoside adenosine $[3,4]$. Human pregnancy courses with physiological maternal and foetal insulin resistance as an adaptive response to the increasing nutrient requirement by the pregnant women and the growing foetuses [5].

Insulin signalling involves preferential activation of the protein kinase $\mathrm{B}(\mathrm{PKB}) / \mathrm{Akt}$ (Akt) and mitogen-activated protein kinase (MAPK) signalling pathways $[4,6]$. Vascular actions of insulin in the human placenta and umbilical cord vessels (hereafter referred as "foetoplacental vasculature") are of relevance since this vascular bed lacks innervation, and the control of the blood flux results from local release of vasoactive molecules [4, 7]. The mechanisms behind vascular insulin effects include the synthesis of nitric oxide (NO) by the endothelial NO synthase (eNOS) isoform, ATP release, and adenosine-mediated increase of Larginine transport and NO synthesis [4, 8, 9]. Pathologies of pregnancy, such as preeclampsia (PE) [10] and gestational diabetes mellitus (GDM) [4, 11], and abnormal maternal conditions, such as pregestational maternal obesity (PGMO) and maternal obesity in pregnancy [12], show with reduced insulin signalling in the foetoplacental vasculature. In this review, we propose that common signalling mechanisms result in insulin resistance of the human foetoplacental vasculature in these diseases.

\section{Insulin Signalling}

Insulin activates the splice variants A (IR-A) and B (IR-B) of insulin receptors (IRs) in the human foetoplacental vasculature [13]. IR-A and IR-B are expressed in this vascular bed with IR-A showing higher affinity for insulin than that with IR-B $[4,13,14]$. IR activation by $\beta$-subunit autophosphorylation recruits and phosphorylates two protein families, that is, the insulin receptor substrates (IRSs) and the Src homology 2 domain-containing transforming protein 1 (SHc) [15] (Figure 1). IRSs have at least six members (IRS-1 to IRS-6), where IRS-1 and IRS-2 are the most characterized [15]. $\mathrm{SHc}$ corresponds to at least three different proteins (SHcA, $\mathrm{SHcB}$, and $\mathrm{SHcC}$ ), with $\mathrm{SHcA}$ being expressed in mammals as the alternative splicing isoforms SHcA 46, SHcA 52, and SHcA 66 [16]. IRS-1 and IRS-2 are major activators of Akt via phosphatidylinositol 3 kinase (PI3K) compared with a minor effect on 44 and $42 \mathrm{kDa}$ mitogen-activated protein kinases ( $\left.\mathrm{p} 44 / 42^{\mathrm{mapk}}\right)$; instead, SHcA preferentially activates p44/42 $2^{\text {mapk }}$ via the growth factor receptor-bound protein 2 (Grb2) [17]. However, whether stimulation of IR-A or IR-B results in differential SHc or IRS activation and signalling is unknown. The physiological response of most tissues in the human body, including the foetoplacental vasculature, is that activation of $\mathrm{p} 42 / 44^{\mathrm{mapk}}$ and Akt signalling pathways results 


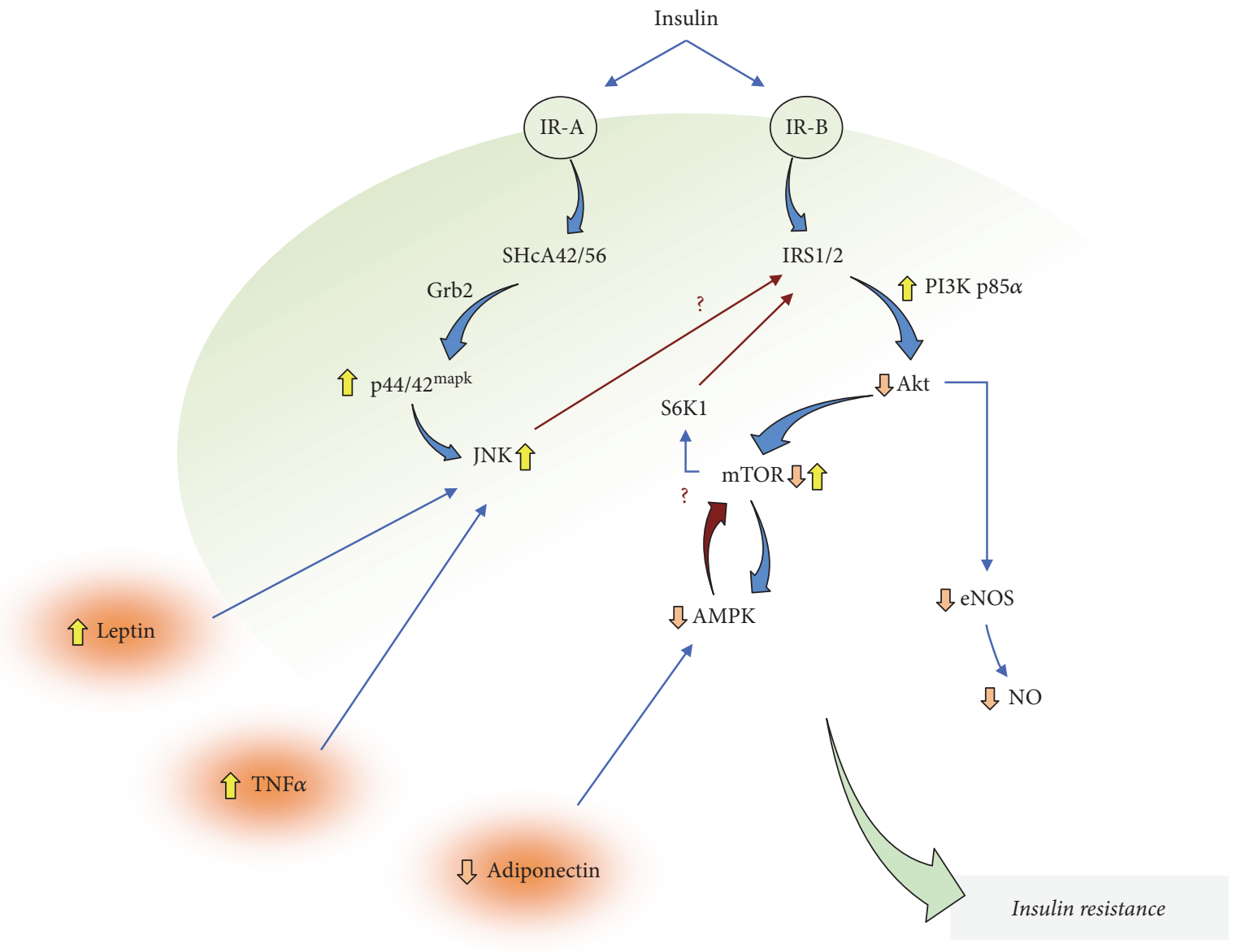

FIGURE 2: Cell signalling in insulin resistance in the human foetoplacental vasculature. Insulin activates insulin receptors A (IR-A) and B (IR-B) leading to recruitment and activation of insulin receptor substrates 1 and 2 (IRS1/2) and Src homology 2 domain-containing transforming protein 1 type A of 42 and $56 \mathrm{kDa}(\mathrm{SHcA} 42 / 56)$. IR-A activation causes preferential activation of SHcA42/56, which triggers signalling through the growth factor receptor-bound protein 2 (Grb2) ending in increased ( $\Uparrow$ ) activity of the 44 and $42 \mathrm{kDa}$ mitogen-protein kinases (p44/42 ${ }^{\text {mapk}}$ ) and c-Jun N-terminal kinases (JNK). IR-B activation causes preferential activation of IRS ${ }^{1 / 2}$ triggering signalling by the p85 $\alpha$ regulatory subunit of phosphatidylinositol 3 kinase (PI3K p85 $\alpha$ ). Activation of this subunit of PI3K decreases ( $\Omega$ ) the protein kinase B/Akt (Akt) activity ending in reduced endothelial nitric oxide (NO) synthase (eNOS) activity and NO generation. Reduced Akt activity also results in lower activity of the mammalian target of rapamycin (mTOR) activity, which turns into reduced activity of the adenosine monophosphate protein kinase (AMPK). Reduced AMPK activity is also caused by the reduced plasma level of adiponectin (an AMPK-activator) thus releasing AMPK-inhibition of mTOR facilitating activation of this molecule. This phenomenon potentially (?) increases mTOR-activated signalling through p70 S6 kinase 1 (S6 K1) thus reducing IRS1/2 signalling. The increased extracellular level of leptin and tumour necrosis factor $\alpha(\mathrm{TNF} \alpha)$ results in JNK activation. The possibility that JNK increases the inhibitor phosphorylation of IRS1/2 $\left(\mathrm{Ser}^{312}\right)$ reducing insulin signalling (?) is likely. All in concert, these mechanisms lead to a state of lower response to insulin of the human foetoplacental vasculature (insulin resistance). Blue arrows denote activation. Red arrows denote inhibition.

in increased eNOS expression and activity leading to vasodilation $[4,18]$. However, under pathological conditions, the equilibrium between signalling associated with IR-A and IR-B activation by insulin is lost and a preferential activation of $\mathrm{p} 42 / 44^{\text {mapk }}$ or Akt is reported. Several studies describe a variety of cell signalling mechanisms potentially involved in these alterations of insulin response; however, upstream- and downstream-associated signalling pathways are not addressed.

\section{Insulin Resistance}

Insulin resistance is seen in subjects where the metabolic handling of D-glucose is deficient [2]. PE [19, 20], GDM
$[21,22]$, and obesity in pregnancy [23] show with insulin resistance in the mother, foetus, and newborn. However, whether insulin resistance results from or is the cause of these pathological conditions is still unclear.

Several studies show that IRS-1-mediated activation of PI3K leads to formation of phosphatidylinositol triphosphate, the substrate for the human 3-phosphoinositidedependent protein kinase 1 (PDK1), which activates Akt [15] (Figure 2). However, in insulin resistance, IR-B preferential activation by insulin results in IRS1/2-mediated increase in the activity of the p $85 \alpha$ regulatory subunit of PI3K (PI3K p85 $\alpha$ ), which inhibits Akt thus reducing NO generation. Other reports show that Akt activation mediates 
increased activity of the mammalian target of rapamycin (mTOR), a regulator of cell proliferation, adhesion, migration, invasion, metabolism, and survival [24]. Interestingly, mTOR signals through p70 S6 kinase 1 (S6K1) which reduces insulin signalling by inhibiting IRSs-activity-mediated activation of Akt $[25,26]$. Thus, a modulatory loop to keep a physiological Akt activity and therefore insulin signalling to cause vasodilation involves mTOR activation/deactivation depending on the state of activation of Akt. When mTOR is upregulated, the physiological consequences are reduced Akt-mediated, NO-dependent vascular responses to insulin.

Other reports address that mTOR activity is inhibited by the adenosine monophosphate kinase (AMPK) [27], a molecule considered as general sensor of the cell energy state getting activated in response to a lower ATP/AMP ratio [28, 29]. AMPK activation results in increased eNOS activator phosphorylation at serine $1177\left(\operatorname{Ser}^{1177}\right)$ and serine $615\left(\operatorname{Ser}^{615}\right)$ in the vasculature [30]. Interestingly, AMPK activation increased the activity of PI3K/Akt/eNOS signalling cascade leading to higher NO generation and prevented the high Dglucose-impaired response to insulin in human umbilical vein endothelial cells (HUVECs) [31]. Thus, it is suggested that AMPK will increase insulin signalling due to its capacity to inhibit mTOR in the human foetoplacental vasculature.

Activation of $\mathrm{p} 44 / 42^{\text {mapk }}$ triggers c-Jun N-terminal kinase (JNK) signalling in HUVECs, resulting in IRS inhibition $[32,33]$ (Figure 2). Since S6K1 activation by mTOR results in p44/42 ${ }^{\text {mapk }}$ - and Akt-reduced activity in HUVECs [34] and insulin-dependent activation of $\mathrm{p} 44 / 42^{\mathrm{mapk}}$ inhibits AMPK in the rat skeletal muscle cell line L6 [35], a functional dependency between $\mathrm{p} 44 / 42^{\mathrm{mapk}}$, AMPK, and mTOR activity may also be a phenomenon involved in impaired insulin sensitivity in the foetoplacental vasculature.

It is well described that proinflammatory cytokine tumour necrosis factor $\alpha(\mathrm{TNF} \alpha)$ [36] and the adipocytokine adiponectin [37] and leptin [38] play crucial roles in insulin resistance. TNF $\alpha$ activates the JNK signalling pathway in HUVECs [39] resulting in inhibition of IRS-1 and reduced Akt-mediated insulin signalling [40-42] (Figure 2). Interestingly, higher plasma TNF $\alpha$ is found late in pregnancy (34-36 weeks of gestation) suggesting a likely reduced insulin biological action at this stage of pregnancy [43]. Adiponectin keeps insulin signalling (i.e., acts as insulin sensitizer) increasing the IRS-dependent signalling pathway by activating AMPK [37] and, subsequently, inhibiting mTOR [44]. Interestingly, a reduced plasma level of adiponectin is reported in pregnant women with diabetes mellitus [36]. Since the maternal plasma TNF $\alpha$ level is elevated in PE [45], GDM [46], or obese pregnant women [47], a potential TNF $\alpha$-dependent inhibition of adiponectin release in insulin resistance in pregnant women, and perhaps the foetus, is likely. However, whether $\mathrm{TNF} \alpha$ regulates adiponectin release in pregnancy is still unknown. Leptin is released in obesity in response to accumulating subcutaneous fat and increased fatty acid oxidation [38], a phenomenon regarded as a state of higher insulin resistance $[38,48]$. Additionally, leptin activates JNK leading to inhibition of IRS1/2 and reduced insulin sensitivity $[32,33]$. Since (i) leptin also increases the generation of reactive oxygen species (ROS) in HUVECs [49], (ii) superoxide anion $\left(\mathrm{O}_{2}^{-}\right)$, the most reactive $\mathrm{ROS}$, scavenges NO [30], and (iii) ROS activates JNK in this cell type [49], a leptin/ROS (probably $\mathrm{O}_{2}^{-}$)/JNK pathway is likely described as a mechanism leading to reduced insulin sensitivity in the human foetoplacental vasculature. Interestingly, increased leptin concentration in the maternal circulation is reported in GDM pregnancies $[50,51]$, a disease that also shows with increased ROS generation $[9,11]$. Thus, this adipocytokine may also play a role in insulin resistance particularly in diseases of pregnancy where ROS generation is increased.

\section{Insulin Resistance in Pregnancy Diseases}

4.1. Preeclampsia. Preeclampsia (PE) is a heterogeneous pregnancy-specific multisystemic syndrome, defined by the occurrence of new onset hypertension $(\geq 140 / 90 \mathrm{mmHg})$ and proteinuria ( $\geq 300 \mathrm{mg} / 24$ hours) after 20 weeks of gestation $[10,52] . \mathrm{PE}$ is of early onset (EOPE, $<34$ weeks of gestation) or late onset (LOPE, $\geq 34$ weeks of gestation) $[10,53,54]$. EOPE and LOPE pregnancies associate with impaired insulin response of the maternal [55] and foetoplacental vasculature $[20,56]$. However, not a clear mechanism explaining these alterations in EOPE and LOPE is yet available.

Preferential activation of $\mathrm{p} 42 / 44^{\text {mapk }}$ and Akt is described in the foetoplacental vasculature from PE. Preterm PE (<37 wg) with HELLP (Hemolysis, Elevated Liver enzymes, and Low Platelet count) courses with increased phosphorylated $\mathrm{p} 42 / 44^{\mathrm{mapk}}$ activation in villous trophoblast [57]. In addition, the maternal plasma level from women with EOPE shows a higher level of endothelin-1 (ET-1) [58], but reduced Akt activity in the placenta [59] (Figure 3). Thus, an ET-1dependent inhibition of Akt reducing insulin signalling is likely in this disease. Furthermore, since Akt activity positively correlates with NO generation in human foetal endothelial cells [60], EOPE-associated foetoplacental vascular dysfunction due to reduced NOS activity may involve p44/42 ${ }^{\text {mapk} / E T-1 / A k t ~ s i g n a l l i n g . ~ O n ~ t h e ~ o t h e r ~ h a n d, ~ L O P E ~}$ pregnancies show with unaltered $\mathrm{p} 42 / 44^{\text {mapk }}$ [57] and unaltered [57] or decreased [61] Akt activity in the placenta. Intriguingly, eNOS protein abundance and activator phosphorylation (Ser ${ }^{1177}$ ) are higher in HUVECs from LOPE pregnancies [20], findings complemented by elevated nitrate/nitrite ratio in human umbilical vein serum $[62,63]$, but contrary to the reported lower nitrate/nitrite ratio [64] and NOS-generation of L-citrulline from L-arginine (index of NOS activity) [20] in this cell type. One plausible explanation for reduced NOS activity in HUVECs from LOPE pregnancies is a predominant functional effect of an increase of eNOS inhibitor ( $\mathrm{Thr}^{495}$ ) compared with the effect of an activator $\left(\operatorname{Ser}^{1177}\right)$ phosphorylation of this enzyme [20]. Earlier studies show increased IRS-1 (Ser $\left.{ }^{312}\right)$ and IRS-2 (Ser $\left.{ }^{731}\right)$ inhibitor phosphorylation in response to insulin in the placenta from LOPE pregnancies [65]. Since IRS1/2 are key activators of Akt, LOPE-reduced Akt and NOS activity could involve IRS1/2 inhibition. Thus, LOPE-associated impaired insulin response could result from reduced IRS1/2/Akt/ eNOS signalling in the human foetoplacental vasculature. Since activation of mTOR results in reduced IRS1/2 activity, 


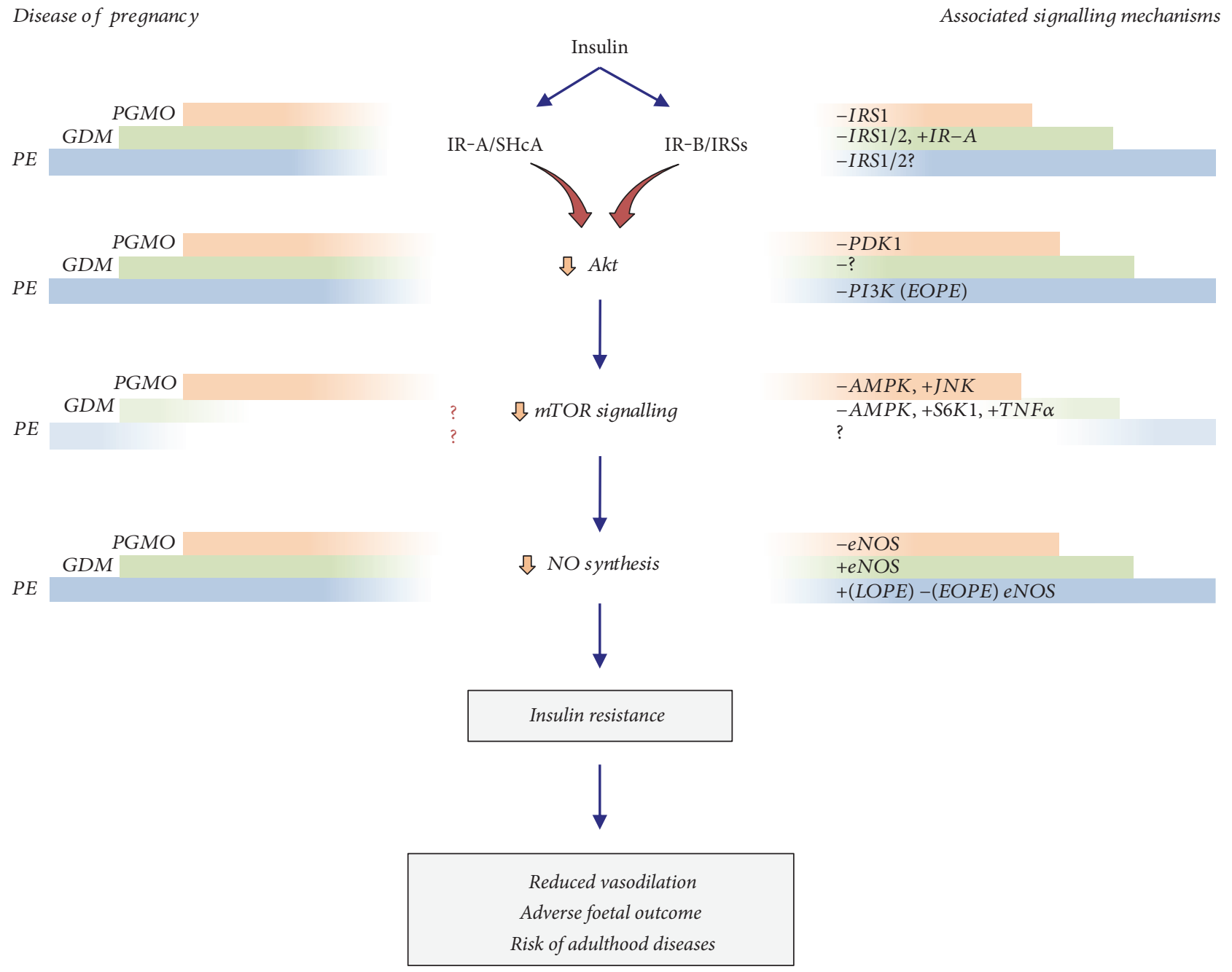

FIGURE 3: Potential involvement of Akt/mTOR in insulin resistance in the human foetoplacental unit from diseases of pregnancy. Pregestational maternal obesity (PGMO), gestational diabetes mellitus (GDM), and preeclampsia are diseases of pregnancy where the human foetoplacental endothelial function is reduced. The response of the placenta to insulin results from activation of insulin receptor A (IR-A) via preferential signalling through Src homology 2 domain-containing transforming protein 1 type A (IR-A/SHcA) and insulin receptor B (IR-B) via preferential signalling through insulin receptor substrates (IR-B/IRSs). The effect of PGMO (represented as orange bars), GDM (represented as green bars), and PE (represented as blue bars) in the cell signalling triggered by insulin causes an increase ( + ) or a decrease ( - ) in the expression and activity of the indicated associated signalling molecules for each pathology. The defective action of insulin is also documented for a reduced $(\preceq)$ activity of protein kinase B/Akt (Akt) due to signalling molecules that are reported for PGMO and early onset PE (EOPE), a phenomenon that is less clear (?) in GDM pregnancies. Reduced Akt activity results in reduced expression and activity of the mammalian target of rapamycin (mTOR) and its signalling in cells from PGMO, with a not clear mechanism (?) in GDM and PE. These changes result in reduced activation of the endothelial nitric oxide (NO) synthase (eNOS) activity leading to lower NO generation in PGMO and EOPE but increased eNOS activity in GDM and late onset PE (LOPE). These mechanisms lead to a reduced Akt/mTOR signalling cascade in response to insulin (insulin resistance) in the foetoplacental vasculature. This condition's outcome is a reduced vasodilation with several other adverse foetal outcomes and higher risk of developing adulthood diseases. PI3K: phosphatidylinositol 3 kinase; AMPK: adenosine monophosphate kinase; SK61: p70 S6 kinase 1; TNF $\alpha$ : tumour necrosis factor $\alpha$; PDK1: human 3-phosphoinositide-dependent protein kinase 1; JNK: c-Jun N-terminal kinases. Specific signalling mechanisms for each molecule shown are described in the text. The magnitude of the bars represents the degree of involvement of the diseases of pregnancy at the corresponding mechanism.

it is likely that this signalling molecule is involved in the effect of EOPE and LOPE on NOS activity. However, there is no information regarding the potential role of mTOR in the aetiology of EOPE or LOPE in this vascular bed.

Several reports support the involvement of circulating factors in the aetiology of $\mathrm{PE}$ including increased soluble
Fms-like tyrosine kinase 1 (sFlt1), soluble endoglin (sEng), and reduced vascular endothelial growth factor (VEGF) plasma levels $[66,67]$. The increased plasma levels of ET-1 and sEng result in a higher sFlt1 plasma level [68]. The latter reduces the availability of free VEGF-A to bind VEGF plasma membrane receptors and inhibition of PI3K/Akt signalling, 
including eNOS activity, in HUVECs [61, 69]. However, inhibition of the PI3K/Akt signalling does not alter sEng release from placenta explants or primary trophoblast in $\mathrm{PE}$ [59]; therefore, a differential response to PI3K/Akt-mediated insulin signalling in human foetoplacental endothelium versus trophoblast is likely. Interestingly, PI3K p 85 phosphorylation at $\mathrm{Tyr}^{688}$ results in increased PI3K activity and Akt signalling in placental tissue from EOPE pregnancies [70]. The latter was proposed as a compensatory mechanism to the VEGF-reduced activation of PI3K/Akt signalling in this disease. However, PI3K p85 activator phosphorylation is unaltered in placentas from LOPE pregnancies [71], suggesting a different adaptive mechanism for insulin signalling in EOPE and LOPE pregnancies.

4.2. Gestational Diabetes Mellitus. GDM refers to any degree of glucose intolerance first recognized during pregnancy, diagnosed at 24-28 weeks of gestation [2]. GDM associates with maternal obesity [72] and high risk of the mother to develop T2DM [73]. GDM presents with clinical manifestations in the mother [74], foetus [75, 76], and newborn [75, 77], including hyperglycaemia and hyperinsulinemia (see also $[78,79])$. It is reported that IR-A expression and insulin receptor $\beta$-subunit ( $\beta$-IR) activity are increased in HUVECs from GDM [80] (Figure 3). Interestingly, the ratio for p44/ $42^{\text {mapk }} /$ Akt is $>1$ due to increased $\mathrm{p} 44 / 44^{\text {mapk }}$, but unaltered Akt activity, suggesting preferential activation of IR-A in this cell type. However, reduced IR-A, but increased IR-B expression, with a $\mathrm{p} 44 / 42^{\mathrm{mapk}} / \mathrm{Akt}$ ratio $<1$ was reported in human placental microvascular endothelium. Insulin restored IR-A and IR-B expression and $\mathrm{p} 44 / 42^{\mathrm{mapk}} / \mathrm{Akt}$ ratio suggesting differential activation of insulin signalling cascades due to differential activation of IR subtypes in the macrovascular and microvascular foetoplacental endothelium from GDM pregnancies.

GDM associates with reduced uptake of the endogenous nucleoside adenosine, a potent vasodilator in most tissues, including the foetoplacental vasculature [4]. This phenomenon results in elevated extracellular concentration of adenosine enough to activate adenosine receptors [81], preferentially $A_{2 A}$ adenosine receptors $\left(A_{2 A} A R\right)$, in the foetoplacental endothelium from GDM pregnancies [4, 11]. Interestingly, GDM also increases hCAT-1-mediated Larginine transport in HUVECs [82], which seems to link with an increased eNOS activity and NO synthesis in this cell type. The latter study also shows that insulin reversed the GDM-increased L-arginine transport requiring $\mathrm{A}_{1} \mathrm{AR}$ activation. Thus, different adenosine receptors are involved in the modulation of L-arginine transport in HUVECs from normal compared with GDM pregnancies.

AMPK activation is lower in the placenta from women with GDM $[83,84]$. This finding is complemented by high levels of TNF- $\alpha$ and activation of NF- $\kappa \mathrm{B}$, conditions leading to increased synthesis of mediators of inflammation and impaired insulin action [85, 86]. Thus, reduced AMPK expression could associate with a proinflammatory state and insulin resistance in GDM pregnancies. Since AMPK inhibits mTOR activity $[27,44]$, a reduced AMPK activation could result in increased mTOR activity in GDM. GDM also courses with hyperleptinemia in the placenta $[87,88]$ and reduced adiponectin level [89] in umbilical vein plasma. However, precise mechanisms at insulin signalling in this disease are unclear.

Insulin treatment of women with GDM (i.e., patients under insulin therapy) reverses the GDM-associated maternal and foetal hyperglycaemia and the increase in IRS-1 and PI3K p $85 \alpha$ activity caused by this disease to values in normal pregnancies [90]. However, the elevated level of leptin in the foetal plasma and TNF- $\alpha$ and IL- $1 \beta$ levels in the placenta from GDM pregnancies were unaltered by insulin therapy. Thus, insulin therapy results in normalization of foetal and maternal glycaemia but does not restore the impaired insulin signalling in foetoplacental endothelium in this disease. Indeed, we recently reported that insulin therapy in women with GDM did not restore the increased Larginine uptake and NO synthesis seen in HUVECs from women with GDM under a controlled diet [91]. It is worrying that a higher chance to be born large for gestational age is reported as an outcome for insulin therapy [92] or in pregnant women treated with insulin and metformin [93] and in a larger number $(\sim 25 \%)$ of infants showing one or more episodes with neonatal morbidity where neonatal asymptomatic hypoglycaemia was the most frequent [94]. We emphasize our call regarding the still unclear effect of maternal insulin therapy on foetus development, the newborn, and postnatal life $[2,4,9,91,95]$.

4.3. Pregestational Maternal Obesity. The World Health Organization defines obesity as individuals with a body mass index $(\mathrm{BMI})>30 \mathrm{~kg} / \mathrm{m}^{2}$, a disease that has reached epidemic characteristics worldwide [1]. One of the main risks of an abnormal nutritional state is its association with metabolic syndrome, a condition with high multiple risk factors for chronic diseases, including diabetes mellitus, cardiovascular diseases, stroke, hypertension, and cancer [96].

Few studies address cell signalling in PGMO. Epidemiological evidence shows that children born to PGMO pregnancies show hyperinsulinemia and elevated insulin resistance $[97,98]$. Additionally, infants and adolescents from PGMO pregnancies exhibit high risk of developing obesity $[99,100]$ and associate with higher cardiovascular risk in adulthood [100]. Interestingly, umbilical cords from PGMO pregnancies show a gene profile related with reduced insulin sensitivity [101], including downregulation of PDPK1 (coding for PDK1) involved in D-glucose uptake and storage [101]. However, direct functional evidence for insulin effect on foetoplacental endothelium in PGMO is limited (Table 1).

PGMO pregnancies associate with reduced activity of AMPK [102] but increased activity of mTOR [103] in the placenta. These findings correlate with reduced maternal plasma adiponectin levels [104]. Since JNK activation is also increased in human placentas from PGMO pregnancies [105], a potential insulin resistance condition resulting from IRS inhibition may involve adiponectin-reduced leveldependent AMPK inactivation, increased mTOR activity, and reduced Akt signalling, in this abnormal condition of pregnancy (Figure 3). 
TABLE 1: Effect of pathologies of pregnancy on insulin signalling in the human foetoplacental vasculature.

\begin{tabular}{|c|c|c|c|c|}
\hline Cell or tissue & Molecule or activity & $\begin{array}{l}\text { Effect of the } \\
\text { pathology }\end{array}$ & $\begin{array}{l}\text { Effect of } \\
\text { insulin }\end{array}$ & References \\
\hline \multicolumn{5}{|l|}{ Preeclampsia } \\
\hline Placenta (EOPE) & $\mathrm{p} 44 / 42^{\mathrm{mapk}}$ & Increase & $n a$ & [57] \\
\hline Placenta (EOPE) & $\mathrm{ET}-1, \mathrm{ET}_{\mathrm{A}}$, and $\mathrm{ET}_{\mathrm{B}}(\mathrm{mRNA})$ & Increase & na & [108] \\
\hline Placenta & Akt-Ser ${ }^{473}$ & Decrease & na & {$[61]$} \\
\hline Placenta & eNOS & Increase & na & [109] \\
\hline Placenta (LOPE) & $\begin{array}{c}\beta \text {-IR, IRS-1-Tyr }{ }^{465}, \text { IRS-1-Ser }^{312} \\
\text { and IRS-2-Ser }\end{array}$ & No effect & Increase & {$[65]$} \\
\hline Placenta (LOPE) & Akt-Ser ${ }^{473}$ & No effect & Increase & {$[110]$} \\
\hline HUVECs (LOPE) & eNOS-Thr ${ }^{495}$, eNOS-Ser $^{1177}$ & Increase & Restored & {$[20]$} \\
\hline HUVECs (LOPE) & eNOS-Ser ${ }^{1177}$ & Increase & na & {$[111]$} \\
\hline HUVECs (EOPE) & eNOS & Decrease & na & {$[111]$} \\
\hline HUVECs & eNOS & Decrease & na & {$[112]$} \\
\hline HUVECs (LOPE) & L-Arginine transport & Increase & Restored & [20] \\
\hline HUVECs (LOPE)* & hCAT-1 & Increase & Increase & {$[20]$} \\
\hline \multicolumn{5}{|l|}{ Gestational diabetes mellitus } \\
\hline Placenta & IRs & Increase & na & [113] \\
\hline Placenta (insulin therapy)** & $\beta$-IR & Increase & Restored & {$[90]$} \\
\hline Placenta & IRS-1 & Increase & na & {$[113]$} \\
\hline Placenta (insulin therapy) & IRS-1 & Increase & Restored & [90] \\
\hline Placenta (insulin therapy) & IRS-2 & Increase & Increase & {$[90]$} \\
\hline Placenta & PI3K p $85 \alpha$ & Increase & Restored & {$[90]$} \\
\hline Placenta & PI3K p $85 \alpha$ & Increase & na & [113] \\
\hline Placenta (insulin therapy) & PI3K p110 & Increase & No effect & {$[90]$} \\
\hline Placenta $^{* * *}$ & mTOR-Ser ${ }^{2448}$, S6K1-Thr ${ }^{421} / \operatorname{Ser}^{424}$ & Increase & na & {$[83]$} \\
\hline Placenta**** & S6 K1-Thr ${ }^{389}, 4$ EBP1-Thr ${ }^{37 / 46}$ & Increase & $n a$ & {$[114]$} \\
\hline Placenta*** & 4EBP1-Thr ${ }^{37 / 46}$ & Increase & na & {$[83]$} \\
\hline Placenta & AMPK (mRNA) & Decrease & na & {$[88]$} \\
\hline Placenta & Adiponectin & Decrease & na & [115] \\
\hline Placenta & TNF- $\alpha$ & Increase & na & {$[85,116]$} \\
\hline Placenta (insulin therapy) & TNF- $\alpha$ & Unaltered & na & [86] \\
\hline Placenta & IL-1 $\beta$ & Increase & na & {$[116]$} \\
\hline Placenta & Leptin receptor & Increase & na & {$[88]$} \\
\hline Trophoblast & Leptin receptor & Increase & na & {$[87]$} \\
\hline HUVECs & IR-A (mRNA) & Increase & Restored & {$[21]$} \\
\hline HUVECs & Akt-Ser ${ }^{473}$ & No effect & Increase & {$[80]$} \\
\hline HUVECs & eNOS, eNOS-Ser ${ }^{1177}$ & Increase & Restored & {$[80]$} \\
\hline HUVECs & $\mathrm{p} 44 / 42^{\mathrm{mapk}}-\mathrm{Thr}^{202 / 204}$ & Increase & Restored & {$[80]$} \\
\hline HUVECs (insulin therapy) & eNOS, eNOS-Ser ${ }^{1177}$ & Increase & Restored & {$[117]$} \\
\hline HUVECs & hENT1, adenosine transport & Decrease & Increase & {$[21,80]$} \\
\hline HUVECs & L-Arginine transport & Increase & Restored & {$[82]$} \\
\hline HUVECs (insulin therapy) & L-Arginine transport & Increase & Restored & {$[117]$} \\
\hline hPMECs & p44/42 ${ }^{\text {mapk }}-$ Thr $^{202 / 204}$, Akt-Ser ${ }^{473}$ & Decrease & Restored & {$[118]$} \\
\hline hPMECs & IR-A (mRNA) & Decrease & Restored & [118] \\
\hline hPMECs & IR-B (mRNA) & Increase & Restored & {$[118]$} \\
\hline hPMECs & hENT1 & Decrease & No effect & {$[118]$} \\
\hline hPMECs & $\mathrm{hENT} 2$ & Decrease & Restored & {$[118]$} \\
\hline hPMECs & hENT1 transport activity & Decrease & No effect & {$[118]$} \\
\hline
\end{tabular}


TABLE 1: Continued.

\begin{tabular}{|c|c|c|c|c|}
\hline Cell or tissue & Molecule or activity & $\begin{array}{l}\text { Effect of the } \\
\text { pathology }\end{array}$ & $\begin{array}{l}\text { Effect of } \\
\text { insulin }\end{array}$ & References \\
\hline hPMECs & hENT2 transport activity & Decrease & Restored & {$[118]$} \\
\hline Umbilical cord plasma & Leptin & Increase & na & {$[88]$} \\
\hline Umbilical cord plasma & Adiponectin & Decrease & na & {$[89]$} \\
\hline \multicolumn{5}{|c|}{ Pregestational maternal obesity } \\
\hline Placenta & AMPK-Thr ${ }^{172}$ & Decrease & na & {$[102,103]$} \\
\hline Placenta & AMPK & Decrease & na & {$[103]$} \\
\hline Placenta & S6 K1-Thr ${ }^{389}$ & Increase & na & {$[88,119]$} \\
\hline Placenta & JNK-Thr ${ }^{183} / \operatorname{Tyr}^{185}$ & Increase & na & [119] \\
\hline Placenta & mTOR (mRNA) & Decrease & na & {$[102,103]$} \\
\hline Placenta & IRS-1 (mRNA) & Decrease & na & [103] \\
\hline
\end{tabular}

AMPK: adenosine monophosphate protein kinase; AMPK-Thr ${ }^{172}$ : AMPK phosphorylated at threonine 172; S6K1: S6 kinase 1; S6K1-Thr ${ }^{421} / \mathrm{Ser}^{424}$ : S6K1 phosphorylated at threonine 421 and serine 424 ; S6K1-Thr ${ }^{389}$ : S6K1 phosphorylated at threonine 389; JNK: c-Jun N-terminal kinases; JNK-Thr ${ }^{183} / \mathrm{Tyr}^{185}$ : JNK phosphorylated at threonine 183 and tyrosine 185; mTOR: mammalian target of rapamycin; IRS-1: insulin receptor substrate 1; IRS-1-Tyr ${ }^{465}$ : IRS-1 phosphorylated at tyrosine 465 ; IRS-1-Ser ${ }^{312}$ : IRS-1 phosphorylated at serine 312; IRS-2: insulin receptor substrate 2 ; IRS-2-Ser ${ }^{731}$ : IRS-2 phosphorylated at serine 731; EOPE: early-onset preeclampsia; LOPE: late-onset preeclampsia; $\mathrm{p} 44 / 42^{\text {mapk }}$ : 44 and $42 \mathrm{kDa}$ mitogen-activated protein kinases; $444 / 42^{\text {mapk }}$ $\mathrm{Thr}^{202 / 204}$ : $\mathrm{p}^{\mathrm{mapk}}$ phosphorylated at threonine 202 and $\mathrm{p} 42^{\mathrm{mapk}}$ phosphorylated at threonine 204; Akt: protein kinase B/Akt; Akt-Ser ${ }^{473}$ : Akt phosphorylated at serine 473; eNOS: endothelial nitric oxide synthase; eNOS-Thr ${ }^{495}$ : eNOS phosphorylated at threonine 495 ; eNOS-Ser ${ }^{1177}$ : eNOS phosphorylated at serine 1177; IRs: insulin receptors; IR-A: insulin receptor A; IR-B: insulin receptor B; $\beta$-IR: insulin receptor $\beta$-subunit; PI3K: phosphatidylinositol 3 kinase; PI3K p85 $\alpha$ : p $85 \alpha$ regulatory subunit of PI3K; PI3K p110: p110 catalytic subunit of PI3K; EGFR: epidermal growth factor receptor; mTOR-Ser ${ }^{2448}$ : mTOR phosphorylated at serine 2448; S6K1-Tyr ${ }^{389}$ : S6K1 phosphorylated at threonine 389; 4EBP1: eukaryotic translation initiation factor $4 \mathrm{E}$ binding protein $1 ; 4 \mathrm{EBP} 1-\mathrm{Thr}^{37 / 46}$ : $4 \mathrm{EBP} 1$ phosphorylated at threonine 37 and 46; TNF- $\alpha$ : tumour necrosis factor $\alpha$; AP1: activator protein 1 ; NF- $\kappa$ B: nuclear factor-kappa B; ET-1: endothelin $1 ; \mathrm{ET}_{\mathrm{A}}$ : endothelin receptor type $\mathrm{A} ; \mathrm{ET}_{\mathrm{B}}$ : endothelin receptor type $\mathrm{B}$; IL- $1 \beta$ : interleukin $1 \beta$; hCAT-1: human cationic amino acid transporter 1; hENT1: human equilibrative nucleoside transporters 1; hENT2: human equilibrative nucleoside transporters 2; HUVECs: human umbilical vein endothelial cells; hPMECs: human placental microvascular endothelial cells. ${ }^{*}$ Cells incubated with insulin in the presence of $\mathrm{ZM}-241385$ ( $\mathrm{A}_{2 \mathrm{~A}} \mathrm{AR}$ antagonist). ${ }^{* *} \mathrm{GDM}$ mothers were obese. ${ }^{* * *}$ Results include GDM mother under diet and insulin therapy. ${ }^{* * *}$ GDM mother on oral insulin-sensitizing antidiabetic undefined medication. na: not assayed.

\section{Concluding Comments}

Insulin regulates canonical signal transduction pathways initiated by activation of IR-A/p44/42 mapk and IR-B/Akt in human foetoplacental vasculature in healthy pregnancies (Figure 3). IRS-1 and IRS-2 are upstream activators of the $\mathrm{PI} 3 \mathrm{~K} / \mathrm{Akt}$ signalling pathway leading to activation of mTOR. SHcA 42 and SHcA 56 activate p44/42 ${ }^{\text {mapk }}$ leading to increased release of vasoconstrictors, such as ET-1. Insulin resistance associated with $\mathrm{PGMO}, \mathrm{PE}$, and GDM results in foetoplacental vascular dysfunction and altered vascular reactivity to insulin. A likely potential common point in insulin resistance in these diseases is a reduced Akt signalling resulting in lower activation of $\mathrm{mTOR}$ and eNOS. A role for AMPK in this phenomenon is not clear, but the involvement of this molecule is likely since its activation positively correlates with mTOR activity. A role of NO in the response to insulin in the foetoplacental endothelium in diseases of pregnancy is well described $[4,10,12]$. Thus, modulation of $\mathrm{NO}$ generation could be a final target of an abnormal IR-A/ $\mathrm{SHcA} / \mathrm{p} 44 / 42^{\text {mapk }}$ - and IR-B/IRSs/Akt-mediated signalling via $A k t / m T O R$ in insulin resistance at the human foetoplacental vasculature. A therapy targeting these signalling molecules could be beneficial to improve insulin response in these diseases. PGMO is a risk factor for developing PE [106, 107] and GDM [107]. Thus, characterizing potential common signalling mechanisms for PGMO, PE, and GDM will facilitate the design of an approach to prevent insulin resistance in the co-occurrence of these or other disorders in pregnancy, thus reducing or abolishing their deleterious consequences for the mother, the foetus, and the newborn.

\section{Conflicts of Interest}

The authors confirm that there are no conflicts of interest.

\section{Authors' Contributions}

Roberto Villalobos-Labra, Luis Silva, and Luis Sobrevia conceived and designed the study. Roberto Villalobos-Labra, Mario Subiabre, Luis Silva, Joaquín Araos, Tamara Sáez, Bárbara Fuenzalida, Marcelo González, Rocío Salsoso, and Andrea Leiva acquired the data/information. Roberto Villalobos-Labra, Mario Subiabre, Luis Silva, Fernando Toledo, Delia I. Chiarello, Joaquín Araos, Tamara Sáez, Bárbara Fuenzalida, Marcelo González, Fabían Pardo, Rocío Salsoso, Claudia Quezada, Andrea Leiva, and Luis Sobrevia analyzed the data/information. Roberto Villalobos-Labra, Mario Subiabre, Luis Silva, Rocío Salsoso, Joaquín Araos, Bárbara Fuenzalida, Fabían Pardo, Claudia Quezada, Andrea Leiva, and Luis Sobrevia interpreted the data/information. Roberto Villalobos-Labra, Mario Subiabre, Luis Silva, Rocío Salsoso, and Luis Sobrevia compiled the tables. Roberto Villalobos-Labra, Luis Silva, and Luis Sobrevia designed the figures. Roberto Villalobos-Labra, Luis Silva, and Luis Sobrevia wrote the manuscript. 


\section{Acknowledgments}

The authors thank Mrs. Amparo Pacheco from CMPL, Pontificia Universidad Católica de Chile (PUC), for the excellent technical and secretarial assistance. This work was supported by the Fondo Nacional de Desarrollo Científico y Tecnológico (FONDECYT 1150377, 1150344, 3160194, 11150083), Chile. This project has received funding from the Marie Curie International Research Staff Exchange Scheme with the 7th European Community Framework Program (Grant Agreement no. 295185-EULAMDIMA), the Netherlands. Roberto Villalobos-Labra, Mario Subiabre, Luis Silva, Tamara Sáez, and Rocío Salsoso hold the Comisión Nacional de Investigación en Ciencia y Tecnología (CONICYT) PhD fellowships (Chile). Rocío Salsoso, Luis Silva, and Bárbara Fuenzalida hold Faculty of Medicine, PUC-PhD fellowships (Chile). Tamara Sáez and Luis Silva hold UMCG University of Groningen Postgraduate School$\mathrm{PhD}$ fellowships (the Netherlands).

\section{References}

[1] American Diabetes Association (ADA), "Classification and diagnosis of diabetes," Diabetes Care, vol. 40, pp. S11-S24, 2017.

[2] World Health Organization (WHO), "Global status report on noncommunicable diseases 2014," World Health, vol. 176, 2014.

[3] R. Muniyappa and J. R. Sowers, "Role of insulin resistance in endothelial dysfunction," Reviews in Endocrine \& Metabolic Disorders, vol. 14, pp. 5-12, 2013.

[4] L. Silva, M. Subiabre, J. Araos et al., "Insulin/adenosine axis linked signalling," Molecular Aspects of Medicine, vol. 55, pp. 45-61, 2017.

[5] A. D. Sonagra, S. M. Biradar, K. Dattatreya, and D. S. J. Murthy, "Normal pregnancy- a state of insulin resistance," Journal of Clinical and Diagnostic Research, vol. 8, pp. CC01-CC03, 2014.

[6] K. J. Mather, H. O. Steinberg, and A. D. Baron, "Insulin resistance in the vasculature," The Journal of Clinical Investigation, vol. 123, pp. 1003-1004, 2013.

[7] S. B. Fox and T. Y. Khong, "Lack of innervation of human umbilical cord. An immunohistological and histochemical study," Placenta, vol. 11, pp. 59-62, 1990.

[8] M. S. Hanson, A. H. Stephenson, E. A. Bowles, and R. S. Sprague, "Insulin inhibits human erythrocyte cAMP accumulation and ATP release: role of phosphodiesterase 3 and phosphoinositide 3-kinase," Experimental Biology and Medicine, vol. 235, pp. 256-262, 2010.

[9] L. Sobrevia, R. Salsoso, T. Sáez, C. Sanhueza, F. Pardo, and A. Leiva, "Insulin therapy and fetoplacental vascular function in gestational diabetes mellitus," Experimental Physiology, vol. 100, pp. 231-238, 2015.

[10] R. Salsoso, M. Farías, J. Gutiérrez et al., “Adenosine and preeclampsia," Molecular Aspects of Medicine, vol. 55, pp. 126139, 2017.

[11] L. Antonioli, C. Blandizzi, B. Csóka, P. Pacher, and G. Haskó, "Adenosine signalling in diabetes mellitus-pathophysiology and therapeutic considerations," Nature Reviews. Endocrinology, vol. 11, pp. 228-241, 2015.
[12] F. Pardo, R. Villalobos-Labra, D. I. Chiarello et al., "Molecular implications of adenosine in obesity," Molecular Aspects of Medicine, vol. 55, pp. 90-101, 2017.

[13] F. Westermeier, T. Sáez, P. Arroyo et al., "Insulin receptor isoforms: an integrated view focused on gestational diabetes mellitus," Diabetes/Metabolism Research and Reviews, vol. 32, pp. 350-365, 2016.

[14] L. Mosthaf, K. Grako, T. J. Dull, L. Coussens, A. Ullrich, and M. C. DA, "Functionally distinct insulin receptors generated by tissue-specific alternative splicing," The EMBO Journal, vol. 9, pp. 2409-2413, 1990.

[15] J. Boucher, A. Kleinridders, and C. R. Kahn, "Insulin receptor signaling in normal and insulin-resistant states," Cold Spring Harbor Perspectives in Biology, vol. 6, article a009191, 2014.

[16] K. S. Ravichandran, "Signaling via Shc family adapter proteins," Oncogene, vol. 20, pp. 6322-6330, 2001.

[17] S. H. Ong, Y. R. Hadari, N. Gotoh, G. R. Guy, J. Schlessinger, and I. Lax, "Stimulation of phosphatidylinositol 3-kinase by fibroblast growth factor receptors is mediated by coordinated recruitment of multiple docking proteins," Proceedings of the National Academy of Sciences of the United States of America, vol. 98, pp. 6074-6079, 2001.

[18] L. Sobrevia, R. Salsoso, B. Fuenzalida et al., "Insulin is a key modulator of fetoplacental endothelium metabolic disturbances in gestational diabetes mellitus," Frontiers in Physiology, vol. 7, p. 119, 2016.

[19] J. M. Roberts, L. M. Bodnar, T. E. Patrick, and R. W. Powers, "The role of obesity in preeclampsia," Pregnancy Hypertens, vol. 1, pp. 6-16, 2011.

[20] R. Salsoso, E. Guzmán-Gutiérrez, T. Sáez et al., "Insulin restores 1-arginine transport requiring adenosine receptors activation in umbilical vein endothelium from late-onset preeclampsia," Placenta, vol. 36, pp. 287-296, 2015.

[21] F. Westermeier, C. Salomón, M. González et al., "Insulin restores gestational diabetes mellitus-reduced adenosine transport involving differential expression of insulin receptor isoforms in human umbilical vein endothelium," Diabetes, vol. 60, pp. 1677-1687, 2011.

[22] Q. Wang, R. Huang, B. Yu et al., "Higher fetal insulin resistance in Chinese pregnant women with gestational diabetes mellitus and correlation with maternal insulin resistance," PLoS One, vol. 8, article e59845, 2013.

[23] F. Pardo, L. Silva, T. Sáez et al., "Human supraphysiological gestational weight gain and fetoplacental vascular dysfunction," International Journal of Obesity, vol. 39, pp. 12641273, 2015.

[24] J. Karar and A. Maity, "PI3K/AKT/mTOR pathway in angiogenesis," Frontiers in Molecular Neuroscience, vol. 4, p. $51,2011$.

[25] A. Tzatsos, "Raptor binds the SAIN (Shc and IRS-1 NPXY binding) domain of insulin receptor substrate-1 (IRS-1) and regulates the phosphorylation of IRS- 1 at Ser-636/639 by mTOR," The Journal of Biological Chemistry, vol. 284, pp. 22525-22534, 2009.

[26] S. J. Kim, M. A. DeStefano, W. J. Oh et al., "mTOR complex 2 regulates proper turnover of insulin receptor substrate-1 via the ubiquitin ligase subunit Fbw8," Molecular Cell, vol. 48, pp. 875-887, 2012.

[27] M. M. Mihaylova and R. J. Shaw, "The AMPK signalling pathway coordinates cell growth, autophagy and metabolism," Nature Cell Biology, vol. 13, pp. 1016-1023, 2011. 
[28] B. Fisslthaler and I. Fleming, "Activation and signaling by the AMP-activated protein kinase in endothelial cells," Circulation Research, vol. 105, pp. 114-127, 2009.

[29] D. G. Hardie and F. A. RossS. A. Hawley, "AMPK: a nutrient and energy sensor that maintains energy homeostasis," Nature Reviews. Molecular Cell Biology, vol. 13, pp. 251262, 2012.

[30] I. Fleming, "Molecular mechanisms underlying the activation of eNOS," Pflugers Archiv-European Journal of Physiology, vol. 459, pp. 793-806, 2010.

[31] Y. Ido, D. Carling, and N. Ruderman, "Hyperglycemiainduced apoptosis in human umbilical vein endothelial cells: inhibition by the AMP-activated protein kinase activation," Diabetes, vol. 51, pp. 159-167, 2002.

[32] F. Andreozzi, E. Laratta, A. Sciacqua, F. Perticone, and G. Sesti, "Angiotensin II impairs the insulin signaling pathway promoting production of nitric oxide by inducing phosphorylation of insulin receptor substrate-1 on Ser312 and Ser616 in human umbilical vein endothelial cells," Circulation Research, vol. 94, pp. 1211-1218, 2004.

[33] V. De Nigris, G. Pujadas, L. La Sala, R. Testa, S. Genovese, and A. Ceriello, "Short-term high glucose exposure impairs insulin signaling in endothelial cells," Cardiovascular Diabetology, vol. 14, p. 114, 2015.

[34] F. Pellegatta, A. L. Catapano, L. Luzi, and I. Terruzzi, "In human endothelial cells amino acids inhibit insulin-induced Akt and ERK1/2 phosphorylation by an mTOR-dependent mechanism," Journal of Cardiovascular Pharmacology, vol. 47, pp. 643-649, 2006.

[35] S. L. Hwang, Y. T. Jeong, X. Li et al., "Inhibitory cross-talk between the AMPK and ERK pathways mediates endoplasmic reticulum stress-induced insulin resistance in skeletal muscle," British Journal of Pharmacology, vol. 169, pp. 6981, 2013.

[36] L. A. Barbour, C. E. McCurdy, T. L. Hernandez, J. P. Kirwan, P. M. Catalano, and J. E. Friedman, "Cellular mechanisms for insulin resistance in normal pregnancy and gestational diabetes," Diabetes Care, vol. 30, pp. 112-119, 2007.

[37] H. Ruan and L. Q. Dong, "Adiponectin signaling and function in insulin target tissues," Journal of Molecular Cell Biology, vol. 8, pp. 101-109, 2016.

[38] A. Yadav, M. A. Kataria, V. Saini, and A. Yadav, "Role of leptin and adiponectin in insulin resistance," Clinica Chimica Acta, vol. 417, pp. 80-84, 2013.

[39] J. Surapisitchat, R. J. Hoefen, X. Pi, M. Yoshizumi, C. Yan, and B. C. Berk, "Fluid shear stress inhibits TNF-alpha activation of JNK but not ERK1/2 or p38 in human umbilical vein endothelial cells: inhibitory crosstalk among MAPK family members," Proceedings of the National Academy of Sciences of the United States of America, vol. 98, pp. 6476-6481, 2001.

[40] V. Aguirre, T. Uchida, L. Yenush, R. Davis, and M. F. White, "The c-Jun NH2-terminal kinase promotes insulin resistance during association with insulin receptor substrate-1 and phosphorylation of Ser307," The Journal of Biological Chemistry, vol. 275, pp. 9047-9054, 2000.

[41] Y. H. Lee, J. Giraud, R. J. Davis, and M. F. White, "c-Jun Nterminal kinase (JNK) mediates feedback inhibition of the insulin signaling cascade," The Journal of Biological Chemistry, vol. 278, pp. 2896-2902, 2003.

[42] K. Hiratani, T. Haruta, A. Tani, J. Kawahara, I. Usui, and M. Kobayashi, "Roles of mTOR and JNK in serine phosphorylation, translocation, and degradation of IRS-1," Biochemical and Biophysical Research Communications, vol. 335, pp. 836-842, 2005.

[43] J. P. Kirwan, S. Hauguel-De Mouzon, J. Lepercq et al., "TNF-alpha is a predictor of insulin resistance in human pregnancy," Diabetes, vol. 51, pp. 2207-2213, 2002.

[44] A. S. Lihn, S. B. Pedersen, and B. Richelsen, "Adiponectin: action, regulation and association to insulin sensitivity," Obesity Reviews, vol. 6, pp. 13-21, 2005.

[45] S. S. Huda, L. E. Brodie, and N. Sattar, "Obesity in pregnancy: prevalence and metabolic consequences," Seminars in Fetal \& Neonatal Medicine, vol. 15, pp. 70-76, 2010.

[46] G. Winkler, K. Cseh, E. Baranyi et al., "Tumor necrosis factor system in insulin resistance in gestational diabetes," Diabetes Research and Clinical Practice, vol. 56, pp. 9399, 2002.

[47] A. Molvarec, A. Szarka, S. Walentin et al., "Serum leptin levels in relation to circulating cytokines, chemokines, adhesion molecules and angiogenic factors in normal pregnancy and preeclampsia," Reproductive Biology and Endocrinology, vol. 9, p. 124, 2011.

[48] H. Askari, G. Tykodi, J. Liu, and S. Dagogo-Jack, "Fasting plasma leptin level is a surrogate measure of insulin sensitivity," The Journal of Clinical Endocrinology and Metabolism, vol. 95, pp. 3836-3843, 2010.

[49] A. Bouloumie, T. Marumo, M. Lafontan, and R. Busse, "Leptin induces oxidative stress in human endothelial cells," The FASEB Journal, vol. 13, pp. 1231-1238, 1999.

[50] A. Kautzky-Willer, G. Pacini, A. Tura et al., "Increased plasma leptin in gestational diabetes," Diabetologia, vol. 44, pp. 164-172, 2001.

[51] J. M. Atègbo, O. Grissa, A. Yessoufou et al., "Modulation of adipokines and cytokines in gestational diabetes and macrosomia," The Journal of Clinical Endocrinology and Metabolism, vol. 91, pp. 4137-4143, 2006.

[52] B. Sibai, G. Dekker, and M. Kupferminc, "Pre-eclampsia," Lancet (London, England), vol. 365, pp. 785-799, 2005.

[53] A. L. Tranquilli, M. A. Brown, G. G. Zeeman, G. Dekker, and B. M. Sibai, "The definition of severe and early-onset preeclampsia. Statements from the International Society for the Study of Hypertension in Pregnancy (ISSHP)," Pregnancy Hypertens, vol. 3, pp. 44-47, 2013.

[54] American College of Obstetrics and Gynecology (ACOG), "Hypertension in pregnancy. Report of the American College of Obstetricians and Gynecologists' Task Force on Hypertension in Pregnancy," Obstetrics and Gynecology, vol. 122, pp. 1122-1131, 2013.

[55] F. R. Abhari, M. Ghanbari Andarieh, A. Farokhfar, and S. Ahmady, "Estimating rate of insulin resistance in patients with preeclampsia using HOMA-IR index and comparison with nonpreeclampsia pregnant women," BioMed Research International, vol. 2014, Article ID 140851, 6 pages, 2014.

[56] M. Scioscia, S. A. Karumanchi, D. Goldman-Wohl, and P. Y. Robillard, "Endothelial dysfunction and metabolic syndrome in preeclampsia: an alternative viewpoint," Journal of Reproductive Immunology, vol. 108, pp. 42-47, 2015.

[57] S. Szabo, M. Mody, R. Romero et al., "Activation of villous trophoblastic $\mathrm{p} 38$ and ERK1/2 signaling pathways in preterm preeclampsia and HELLP syndrome," Pathology Oncology Research, vol. 21, pp. 659-668, 2015. 
[58] L. Zhang, Y. Han, and Y. Han, "Serum soluble endoglin, plasma endothelin-1 and coagulation function in early onset severe preeclampsia with organ dysfunction," Zhongguo Wei Zhong Bing Ji Jiu Yi Xue, vol. 22, pp. 371-374, 2010.

[59] T. J. Kaitu'u-Lino, R. Hastie, N. J. Hannan et al., "Loss of Akt increases soluble endoglin release from endothelial cells but not placenta," Pregnancy Hypertens, vol. 6, pp. 95-102, 2016.

[60] N. L. Huang, S. H. Chiang, C. H. Hsueh, Y. J. Liang, Y. J. Chen, and L. P. Lai, "Metformin inhibits TNF- $\alpha$-induced I $\kappa$ B kinase phosphorylation, I $\kappa$ B- $\alpha$ degradation and IL-6 production in endothelial cells through PI3K-dependent AMPK phosphorylation," International Journal of Cardiology, vol. 134, pp. 169-175, 2009.

[61] M. J. Cudmore, S. Ahmad, S. Sissaoui et al., "Loss of Akt activity increases circulating soluble endoglin release in preeclampsia: identification of inter-dependency between Akt-1 and heme oxygenase-1," European Heart Journal, vol. 33, pp. 1150-1158, 2012.

[62] A. H. Shaamash, E. D. Elsnosy, A. M. Makhlouf, M. M. Zakhari, O. A. Ibrahim, and E L.-d. HM, "Maternal and fetal serum nitric oxide (NO) concentrations in normal pregnancy, pre-eclampsia and eclampsia," International Journal of Gynaecology and Obstetrics, vol. 68, pp. 207-214, 2000.

[63] S. Demircan Sezer, M. Küçük, S. Nergiz Avcıoğlu et al., "Comparison of maternal and umbilical cord blood HIF-1 $\alpha$ and nitric oxide levels in early and late onset preeclamptic pregnancies," Gynecological Endocrinology, vol. 31, pp. 945948, 2015.

[64] J. A. Gonzalez-Garrido Chem, I. M. Olivares-Corichi, J. M. Tovar-Rodriguez et al., "Influence of the AT(2) receptor on the L-arginine-nitric oxide pathway and effects of (-)-epicatechin on HUVECs from women with preeclampsia," Journal of Human Hypertension, vol. 27, pp. 355-361, 2013.

[65] M. Scioscia, K. Gumaa, S. Kunjara et al., "Insulin resistance in human preeclamptic placenta is mediated by serine phosphorylation of insulin receptor substrate-1 and -2," The Journal of Clinical Endocrinology and Metabolism, vol. 91, pp. 709-717, 2006.

[66] S. E. Maynard and S. A. Karumanchi, "Angiogenic factors and preeclampsia," Seminars in Nephrology, vol. 31, pp. 3346, 2011.

[67] S. Rana, S. A. Karumanchi, and M. D. Lindheimer, "Angiogenic factors in diagnosis, management, and research in preeclampsia," Hypertension, vol. 63, pp. 198-202, 2014.

[68] K. Verdonk, L. Saleh, S. Lankhorst et al., "Association studies suggest a key role for endothelin-1 in the pathogenesis of preeclampsia and the accompanying renin-angiotensinaldosterone system suppression," Hypertension, vol. 65, pp. 1316-1323, 2015.

[69] T. Cindrova-Davies, D. A. Sanders, G. J. Burton, and D. S. Charnock-Jones, "Soluble FLT1 sensitizes endothelial cells to inflammatory cytokines by antagonizing VEGF receptormediated signalling," Cardiovascular Research, vol. 89, pp. 671-679, 2011.

[70] B. D. Cuevas, Y. Lu, M. Mao et al., “Tyrosine phosphorylation of p85 relieves its inhibitory activity on phosphatidylinositol 3-kinase," The Journal of Biological Chemistry, vol. 276, pp. 27455-27461, 2001.

[71] R. B. Orcy, S. Schroeder, S. Hofmeister Martins-Costa et al., "Signalization of Akt/PKB in the placenta, skeletal muscle and adipose tissue of preeclampsia patients," Gynecologic and Obstetric Investigation, vol. 66, pp. 231-236, 2008.
[72] S. Y. Chu, W. M. Callaghan, S. Y. Kim et al., "Maternal obesity and risk of gestational diabetes mellitus," Diabetes Care, vol. 30, pp. 2070-2076, 2007.

[73] L. Bellamy, J.-P. Casas, A. D. Hingorani, and D. Williams, "Type 2 diabetes mellitus after gestational diabetes: a systematic review and meta-analysis," Lancet, vol. 373, pp. 17731779, 2009.

[74] P. M. Catalano, E. D. Tyzbir, R. R. Wolfe et al., "Carbohydrate metabolism during pregnancy in control subjects and women with gestational diabetes," The American Journal of Physiology, vol. 264, pp. E60-E67, 1993.

[75] B. L. Silverman, B. E. Metzger, N. H. Cho, and C. A. Loeb, "Impaired glucose tolerance in adolescent offspring of diabetic mothers: relationship to fetal hyperinsulinism," Diabetes Care, vol. 18, pp. 611-617, 1995.

[76] C. Y. Sanhal, H. K. Daglar, O. Kara, D. Uygur, and A. Yucel, "Assessment of fetal myocardial performance index in women with pregestational and gestational diabetes mellitus," The Journal of Obstetrics and Gynaecology Research, vol. 43, pp. 65-72, 2017.

[77] J. S. Sheffield, E. L. Butler-Koster, B. M. Casey, M. I. DD, and K. J. Leveno, "Maternal diabetes mellitus and infant malformations," Obstetrics and Gynecology, vol. 100, pp. 925-930, 2002.

[78] J. L. Nold and M. K. Georgieff, "Infants of diabetic mothers," Pediatric Clinics of North America, vol. 51, pp. 619-637, 2004.

[79] D. Mitanchez, A. Burguet, and U. Simeoni, "Infants born to mothers with gestational diabetes mellitus: mild neonatal effects, a long-term threat to global health," The Journal of Pediatrics, vol. 164, pp. 445-450, 2014.

[80] F. Westermeier, C. Salomón, M. Farías et al., "Insulin requires normal expression and signaling of insulin receptor A to reverse gestational diabetes-reduced adenosine transport in human umbilical vein endothelium," The FASEB Journal, vol. 29, pp. 37-49, 2015.

[81] M. Peleli, B. Fredholm, L. Sobrevia, and M. Carlström, "Pharmacological targeting of adenosine receptor signalling," Molecular Aspects of Medicine, vol. 55, pp. 4-8, 2017.

[82] E. Guzmán-Gutiérrez, A. Armella, F. Toledo, F. Pardo, A. Leiva, and L. Sobrevia, "Insulin requires Al adenosine receptors expression to reverse gestational diabetes-increased Larginine transport in human umbilical vein endothelium," Purinergic Signal, vol. 12, pp. 175-190, 2016.

[83] A. Pérez-Pérez, J. L. Maymo, Y. P. Gambino et al., “Activated translation signaling in placenta from pregnant women with gestational diabetes mellitus: possible role of leptin," Hormone and Metabolic Research, vol. 45, pp. 436-442, 2013a.

[84] G. Yao, Y. Zhang, D. Wang et al., "GDM-induced macrosomia is reversed by Cav-1 via AMPK-mediated fatty acid transport and GLUT1-mediated glucose transport in placenta," PLoS One, vol. 12, 2017.

[85] M. T. Coughlan, K. Oliva, H. M. Georgiou, J. M. Permezel, and G. E. Rice, "Glucose-induced release of tumour necrosis factor-alpha from human placental and adipose tissues in gestational diabetes mellitus," Diabetic Medicine, vol. 18, pp. 921-927, 2001.

[86] M. T. Coughlan, M. Permezel, H. M. Georgiou, and G. E. Rice, "Repression of oxidant-induced nuclear factor- $\kappa \mathrm{B}$ activity mediates placental cytokine responses in gestational diabetes," The Journal of Clinical Endocrinology and Metabolism, vol. 89, pp. 3585-3594, 2004. 
[87] A. Pérez-Pérez, J. Maymó, Y. Gambino et al., "Insulin enhances leptin expression in human trophoblastic cells," Biology of Reproduction, vol. 89, p. 20, $2013 \mathrm{~b}$.

[88] J. Martino, S. Sebert, M. T. Segura et al., "Maternal body weight and gestational diabetes differentially influence placental and pregnancy outcomes," The Journal of Clinical Endocrinology and Metabolism, vol. 101, pp. 59-68, 2016.

[89] R. McManus, K. Summers, B. De Vrijer, N. Cohen, A. Thompson, and I. Giroux, "Maternal, umbilical arterial and umbilical venous 25 -hydroxyvitamin $\mathrm{D}$ and adipocytokine concentrations in pregnancies with and without gestational diabetes," Clinical Endocrinology, vol. 80, pp. 635-641, 2014.

[90] M. Colomiere, M. Permezel, C. Riley, G. Desoye, and M. Lappas, "Defective insulin signaling in placenta from pregnancies complicated by gestational diabetes mellitus," European Journal of Endocrinology, vol. 160, pp. 567-578, 2009.

[91] M. Subiabre, L. Silva, R. Villalobos-Labra et al., "Maternal insulin therapy does not restore foetoplacental endothelial dysfunction in gestational diabetes mellitus," Biochimica et Biophysica Acta Molecular Basis of Disease, 2017.

[92] S. H. Koning, K. Hoogenberg, K. A. Scheuneman et al., "Neonatal and obstetric outcomes in diet- and insulin-treated women with gestational diabetes mellitus: a retrospective study," BMC Endocrine Disorders, vol. 16, p. 52, 2016.

[93] R. T. McGrath, S. J. Glastras, S. Hocking, and G. R. Fulcher, "Use of metformin earlier in pregnancy predicts supplemental insulin therapy in women with gestational diabetes," Diabetes Research and Clinical Practice, vol. 116, pp. 96-99, 2016.

[94] B. Persson, M. Stangenberg, U. Hansson, and E. Nordlander, "Gestational diabetes mellitus (GDM). Comparative evaluation of two treatment regimens, diet versus insulin and diet," Diabetes, vol. 34, pp. 101-105, 1985.

[95] O. Verier-Mine, "Outcomes in women with a history of gestational diabetes. Screening and prevention of type 2 diabetes. Literature review," Diabetes \& Metabolism, vol. 36, pp. 595$616,2010$.

[96] S. M. Grundy, H. B. Brewer, J. I. Cleeman, S. C. Smith Jr., C. Lenfant, and American Heart Association, National Heart, Lung, and Blood Institute, "Definition of metabolic syndrome: report of the national heart, lung, and blood institute/American Heart Association Conference on Scientific Issues Related to Definition," Circulation, vol. 109, pp. 433438, 2004.

[97] P. M. Catalano, L. Presley, J. Minium, and S. Hauguel-de Mouzon, "Fetuses of obese mothers develop insulin resistance in utero," Diabetes Care, vol. 32, pp. 1076-1080, 2009.

[98] L. E. Simental-Mendía, A. Castañeda-Chacón, M. RodríguezMorán, and F. Guerrero-Romero, "Birth-weight, insulin levels, and HOMA-IR in newborns at term," BMC Pediatrics, vol. 12, p. 94, 2012.

[99] J. Pirkola, A. Pouta, A. Bloigu et al., "Risks of overweight and abdominal obesity at age 16 years associated with prenatal exposures to maternal prepregnancy overweight and gestational diabetes mellitus," Diabetes Care, vol. 33, pp. 11151121,2010

[100] R. Gaillard, E. A. P. Steegers, L. Duijts et al., "Childhood cardiometabolic outcomes of maternal obesity during pregnancy: the generation R study," Hypertension, vol. 63, pp. 683-691, 2014.
[101] K. M. Thakali, J. Saben, J. B. Faske et al., "Maternal pregravid obesity changes gene expression profiles toward greater inflammation and reduced insulin sensitivity in umbilical cord," Pediatric Research, vol. 76, pp. 202-210, 2014.

[102] J. Saben, F. Lindsey, Y. Zhong et al., "Maternal obesity is associated with a lipotoxic placental environment," Placenta, vol. 35, pp. 171-177, 2014.

[103] N. Jansson, F. J. Rosario, F. Gaccioli et al., "Activation of placental mTOR signaling and amino acid transporters in obese women giving birth to large babies," The Journal of Clinical Endocrinology and Metabolism, vol. 98, pp. 105-113, 2013.

[104] N. Jansson, A. Nilsfelt, M. Gellerstedt et al., "Maternal hormones linking maternal body mass index and dietary intake to birth weight," The American Journal of Clinical Nutrition, vol. 87, pp. 1743-1749, 2008.

[105] J. Saben, Y. Zhong, H. Gomez-Acevedo et al., "Early growth response protein-1 mediates lipotoxicity-associated placental inflammation: role in maternal obesity," The American Journal of Physiology, vol. 305, pp. E1-E14, 2013.

[106] E. Paré, S. Parry, T. F. McElrath, D. Pucci, A. Newton, and K. H. Lim, "Clinical risk factors for preeclampsia in the 21st century," Obstetrics and Gynecology, vol. 124, pp. 763-770, 2014.

[107] T.-H. Hung and T.-T. Hsieh, "Pregestational body mass index, gestational weight gain, and risks for adverse pregnancy outcomes among Taiwanese women: a retrospective cohort study," Taiwanese Journal of Obstetrics \& Gynecology, vol. 55, pp. 575-581, 2016.

[108] M. Dieber-Rotheneder, S. Beganovic, G. Desoye, U. Lang, and M. Cervar-Zivkovic, "Complex expression changes of the placental endothelin system in early and late onset preeclampsia, fetal growth restriction and gestational diabetes," Life Sciences, vol. 91, pp. 710-715, 2012.

[109] W. Xiang, H. Chen, X. Xu, M. Zhang, and R. Jiang, "Expression of endothelial nitric oxide synthase traffic inducer in the placentas of women with pre-eclampsia," International Journal of Gynaecology and Obstetrics, vol. 89, pp. 103-107, 2005.

[110] G. D. Ferreira, R. B. Orcy, S. H. Martins-Costa et al., "Insulin stimulation of Akt/PKB phosphorylation in the placenta of preeclampsia patients," São Paulo Medical Journal, vol. 129, pp. 387-391, 2011.

[111] C. Escudero, P. Bertoglia, M. Hernadez et al., "Impaired A2A adenosine receptor/nitric oxide/VEGF signaling pathway in fetal endothelium during late- and early-onset preeclampsia," Purinergic Signal, vol. 9, pp. 215-226, 2013.

[112] X. Wang, N. Athayde, and B. Trudinger, "Maternal plasma from pregnant women with umbilical placental vascular disease does not affect endothelial cell mRNA expression of nitric oxide synthase," Journal of the Society for Gynecologic Investigation, vol. 11, pp. 149-153, 2004.

[113] A. Alonso, C. González Del Rey, A. Navarro, J. Tolivia, and C. G. González, "Effects of gestational diabetes mellitus on proteins implicated in insulin signaling in human placenta," Gynecological Endocrinology, vol. 22, pp. 526535, 2006.

[114] L. Sati, B. Soygur, and C. Celik-Ozenci, "Expression of mammalian target of rapamycin and downstream targets in normal and gestational diabetic human term placenta," Reproductive Sciences, vol. 23, pp. 324-332, 2016.

[115] H. Chen, H. Chen, Y. Wu, B. Liu, Z. Li, and Z. Wang, "Adiponectin exerts antiproliferative effect on human placenta via modulation of the JNK/c-jun pathway," International 
Journal of Clinical and Experimental Pathology, vol. 7, pp. 2894-2904, 2014.

[116] C. Marseille-Tremblay, M. Ethier-Chiasson, J.-C. Forest et al., "Impact of maternal circulating cholesterol and gestational diabetes mellitus on lipid metabolism in human term placenta," Molecular Reproduction and Development, vol. 75, pp. 1054-1062, 2008.

[117] M. Subiabre, R. Salsoso, R. Villalobos-Labra et al., "Insulin therapy fails to reverse the human foetoplacental endothelial dysfunction in gestational diabetes mellitus," Placenta, vol. 51, pp. 117-118, 2017.

[118] C. Salomón, F. Westermeier, C. Puebla et al., "Gestational diabetes reduces adenosine transport in human placental microvascular endothelium, an effect reversed by insulin," PLoS One, vol. 7, article e40578, 2012.

[119] K. E. Brett, Z. M. Ferraro, M. Holcik, and K. B. Adamo, "Placenta nutrient transport-related gene expression: the impact of maternal obesity and excessive gestational weight gain," The Journal of Maternal-Fetal \& Neonatal Medicine, vol. 29, pp. 1399-1405, 2016. 


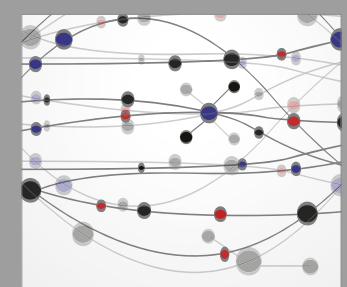

The Scientific World Journal
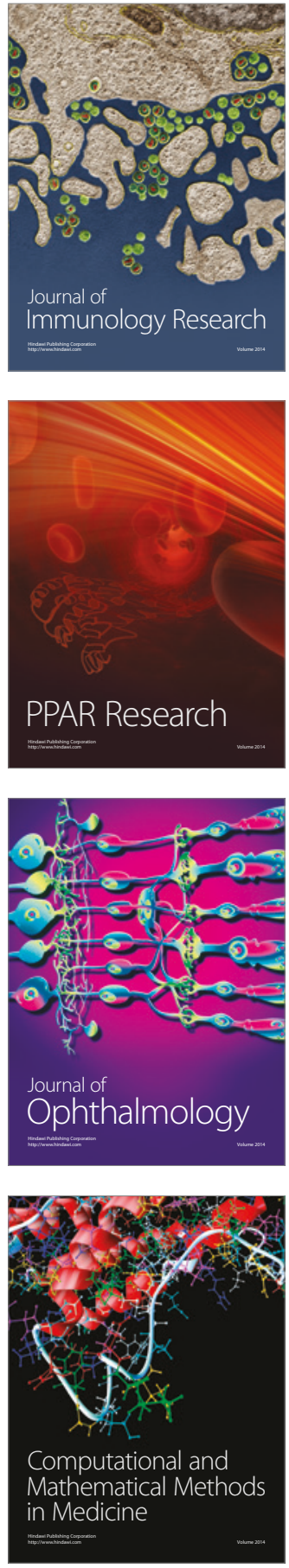

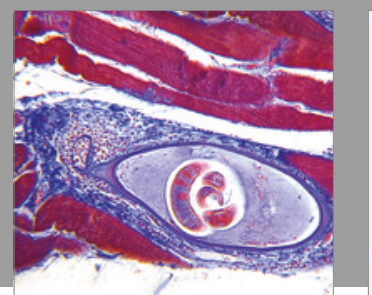

Gastroenterology Research and Practice
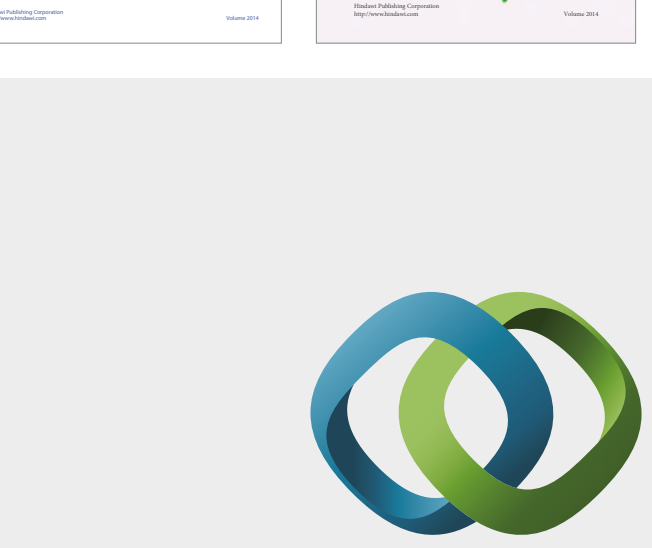

\section{Hindawi}

Submit your manuscripts at

https://www.hindawi.com
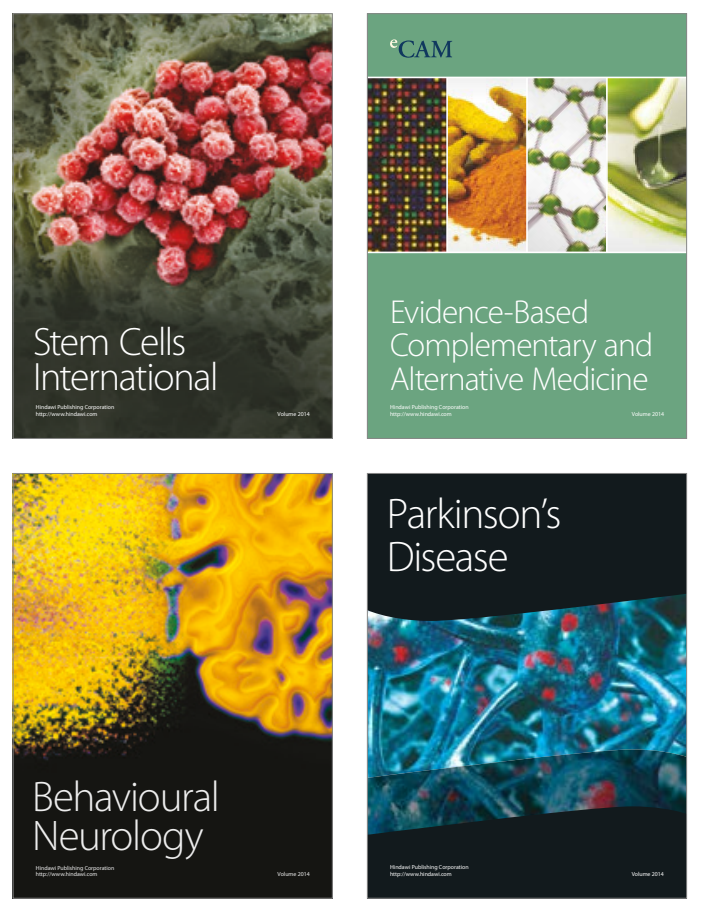
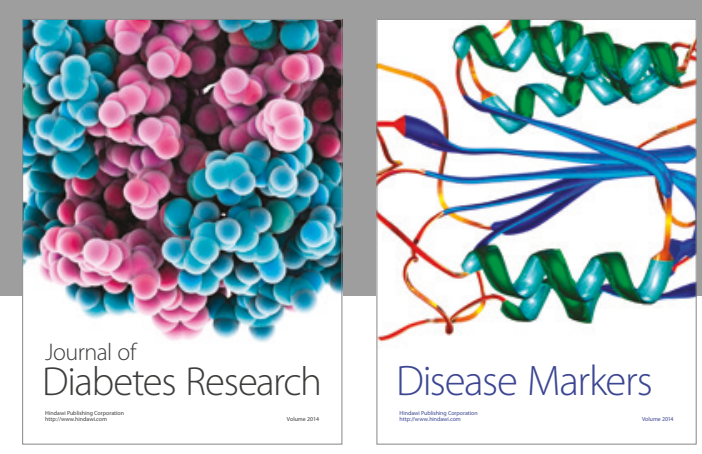

Disease Markers
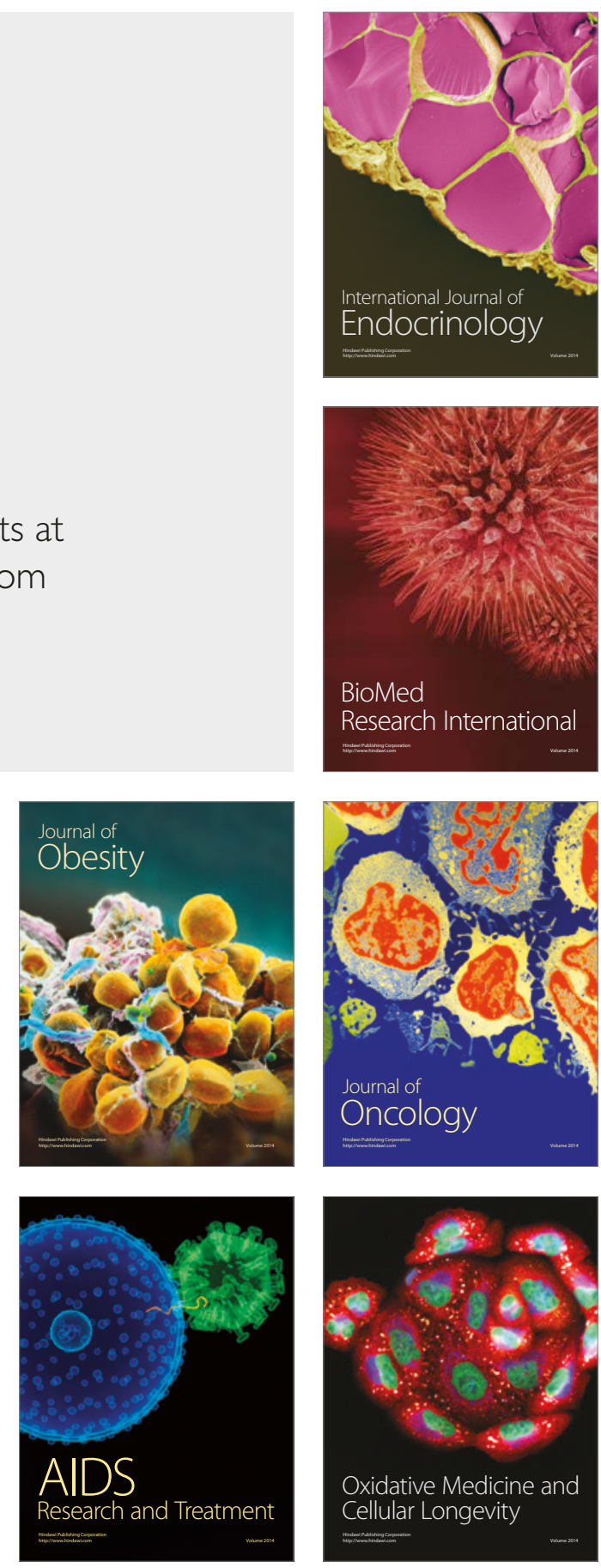